\title{
AC 2008-1319: DEVELOPMENT OF PERFORMANCE CRITERIA FOR ASSESSING PROGRAM OUTCOMES IN ENGINEERING, ENGINEERING TECHNOLOGY \& COMPUTER SCIENCE PROGRAMS
}

\section{Paul Biney, Prairie View A\&M University}

Dr. Paul O. Biney is a Professor in the Mechanical Engineering Department at Prairie View A\&M University, and the Director of the Future Aerospace Science \& Technology (FAST) Center. He is a registered professional engineer in Texas. His areas of expertise include processing, fabrication and characterization of high temperature polymer matrix composites, multifunctional nanocomposites and energy systems design. He is also the chairman of the College of Engineering Assessment Committee and oversees program outcomes assessment in the College of Engineering. Dr. Biney teaches courses in the Thermal Science area.

\section{Raghava Kommalapati, Prairie View A\&M University}

Dr. Raghava Kommalapati is an Associate Professor in Civil and Environmental Engineering and a member of the College of Engineering Assessment Committee.

\section{Michael Gyamerah, Prairie View A\&M University}

Dr. Michael Gyamerah is an Associate Professor in Chemical Engineering and a member of the College of Engineering Assessment Committee.

\section{Annamalai Annamalai, Prairie View A\&M University}

Dr. A. Annamalai is an Associate Professor in Electrical and Computer Engineering and a member of the College of Engineering Assessment Committee.

\section{Pamela Obiomon, Prairie View A\&M University}

Dr. Pamela Obiomon is an Assistant professor in Electrical and Computer Engineering and a member of the College of Engineering Assessment Committee.

\section{Xiaobo Peng, Prairie View A\&M University}

Dr. Xiaobo Peng ia an Assistant Professor in the Mechanical Engineering Department and a member of the College of Engineering Assessment Committee.

Mohan Ketkar, Prairie View A\&M University

Dr. Mohan Ketkar is an Assistant Professor in Engineering Technology and a member of the College of Engineering Assessment Committee.

\section{Nripendra Sarker, Prairie View A\&M University}

Dr. Nripendra Sarker is a Lecturer in Engineering Technology and a member of the College of Engineering Assessment Committee.

\section{Ravindra Iyengar, Prairie View A\&M University}

Mr. Ravindra Iyengar is an Assistant professor in Computer Science and a member of the College of Engineering Assessment Committee. 


\title{
Development of Performance Criteria for Assessing Program Outcomes in Engineering, Engineering Technology and Computer Science Programs
}

\begin{abstract}
This paper presents the development and the use of performance criteria that could be used for detailed assessment of specific students' performance in the program outcomes listed for Engineering programs (EAC Criterion 3, a-k outcomes), Engineering Technology programs (TAC Criterion 2, a-k outcomes) and Computer Science programs (CAC criterion 1, a-i outcomes). Performance criteria have been used to break down each program outcome into concrete measurable actions students are expected to be able to perform to demonstrate proficiency in the outcome. For each of the listed outcomes for the ABET Accreditation bodies, detailed performance criteria are presented in this paper. Suggestions on how the performance criteria can be used in a program are described in detail to allow selective adoption of the performance criteria for different programs and for different courses. The methodology for defining and using the performance criteria enables faculty to (1) fully understand the outcomes, (2) understand a range of performance criteria that need to be measured for each outcome, and (3) remove any ambiguity in the interpretation of the outcomes. In addition, it makes it possible to identify the critical skill-sets to measure for each outcome and makes assessment meaningful to the various programs.
\end{abstract}

\section{Introduction}

In the advent of EC 2000, Engineering, Engineering Technology and Computer Science programs have grappled with methods for assessing the ABET outcomes, especially those skills which are not taught in the traditional programs. Even though several assessment methods have been published in the literature ${ }^{(1,2,3,4)}$ for assessing outcomes, there is still a need to establish concrete performance criteria for the outcomes to make the interpretation of assessment results meaningful. Richard Felder and Rebecca Brent ${ }^{5}$ have provided useful references that provide additional suggestions for defining performance criteria for the outcomes discussed in this paper.

Performance criteria are specific measurable statements that indicate the actions or competencies students should be able to perform or possess at the end of the measurement period. Defining performance criteria for each program outcome is important because it (1) delineates specific statements that identify concrete measurable actions students should be able to perform to meet the outcome, (2) clearly states what needs to be measured, (3) provides common understanding among the faculty on the interpretation of an outcome, thereby removing any ambiguity in the interpretation of an outcome, (4) informs students of the expectations from the outcome, (5) provides focus on the type of data to be collected, (6) provides validity to the assessment results, (7) clearly identifies specific problem areas to be addressed as a result of the assessment process.

To ensure that the performance criteria developed can be used by different programs, they were developed based on the program outcomes for Engineering (ABET Criterion 3, a-k outcomes), Engineering Technology (TAC Criterion 2, a-k outcomes) and Computer Science (CAC criterion 1, a-i outcomes). The program outcomes from the three ABET Accreditation Commissions were analyzed and grouped based on similarities. The performance criteria were developed for each 
similar group of outcomes. In the description provided in this paper, the outcomes were put into twelve groups consisting of outcome group 1 to outcome group 12.

\section{Performance Criteria for Outcome Group 1}

Outcome group 1 consists of (1) EAC Criterion 3, outcome a, "ability to apply the knowledge of mathematics, science, and engineering", (2) TAC Criterion 3, outcome b, "ability to apply current knowledge and adapt to emerging applications of mathematics, science, engineering and technology", and (3) CAC criterion 3, outcome a, "ability to apply knowledge of computing and mathematics appropriate to the discipline". For this outcome group, the performance criteria were based on knowledge and application of mathematics, science, and pre-requisite courses.

The six performance criteria developed for use in measuring this outcome are based on determining whether:

1. Students have the knowledge and the ability to apply basic mathematics involving algebra, geometry, and trigonometry

2. Students have the knowledge and the ability to apply intermediate mathematics involving differential calculus, integral calculus, and probability \& statistics

3. Students have the knowledge and the ability to apply advanced mathematics including complex analysis, numerical analysis, Fourier series, Laplace transforms, and linear algebra

4. Students demonstrate the knowledge and the ability to apply chemistry

5. Students demonstrate the knowledge and the ability to apply physics

6. Students have the knowledge and the ability to apply named prerequisite courses

By measuring the performance of students in these six areas, it is possible to determine, in finer detail, specific areas that may need improvement. Faculty and students are also made aware, and a common ground is created for assessing this outcome.

\section{Performance Criteria for Outcome Group 2}

Outcome group 2 consists of (1) EAC Criterion 3, outcome b, "Ability to design and conduct experiments, as well as to analyze and interpret data", and (2) TAC Criterion 2, outcome c, " an ability to conduct, analyze and interpret experiments and apply experimental results to improve processes". Four performance criteria were developed for this outcome. For each performance criterion, detailed guides for assessing the performance criterion were also provided. The six performance criteria developed for this outcome, are based on determining whether:

\section{Students have the ability to design experiments}

This performance criteria is assessed by determining whether given a phenomenon to be experimentally investigated, the students are able to (i) identify the measurable parameters of the phenomenon, (ii) identify different methods for measuring the phenomenon, (iii) identify and select or design appropriate equipment or components for measuring the parameters, (iv) provide steps for setting up and conducting the experiment, and (v) identify the relationship between the phenomenon and the measured parameters. 


\section{Students have the ability to conduct experiments}

To assess this performance criteria, it is necessary to determine if students are able to (i) demonstrate general lab safety, (ii) follow experimental procedures for the experiment , while maintaining all safety precautions, (iii) demonstrate knowledge of how equipment functions and their limitations, (iv) complete pre-lab assignment before coming to the lab when required, and (v) collect and record data using appropriate units of measurement and identify the dependent and independent variables in the experiment

\section{Students are able to analyze experimental data}

This performance criteria is assessed by students' ability to (i) Analyze the data to generate the required parameters using appropriate units and significant figures, and (ii) use statistical analysis as needed.

\section{Students are able to interpret data}

To measure this outcome, it is necessary to determine students' ability to (i) present the data (raw /derived) in tabular or graphical form to meet the objectives and to aid in interpretation, (ii) discuss the raw and derived data/graphs and assess the validity of the results, (iii) demonstrate the ability to relate how experimental result can be used to improve a process, and (iv) draw appropriate or reasonable conclusions.

\section{Performance Criteria for Outcome Group 3}

Outcome group 3 consists of (1) EAC Criterion 3, outcome c, "an ability to design a system, component, or process to meet desired needs within realistic constraints such as economic, environmental, social, political, ethical, health and safety, manufacturability, and sustainability", (2) TAC Criterion 3, outcome d, " an ability to apply creativity in the design of systems, components or processes appropriate to program educational objectives, and (3) CAC Criterion 3 c, "an ability to design, implement, and evaluate a computer-based system, process, component, or program to meet desired needs. Five performance criteria were developed for this outcome. For each performance criteria, detailed guide for assessing the performance criteria were also provided. The five performance criteria developed for this outcome, are based on

\section{Ability to define the problem}

This performance criterion is assessed by determining if students are able to (i) identify the customer and the needs, (ii) identify and list the design objectives, and (iii) identify the design constraints.

\section{Ability to plan the project}

This performance criterion is also assessed by determining if students are able to (i) define the design strategy and methodology, (ii) identify and break down work into tasks and subtasks, and identify the personnel and deliverables for each, (iii) develop a Gantt chart and critical path analysis for managing the project, (iv) establish major milestones for tracking progress and define performance metrics to measure success. 


\section{Ability to conduct a review of the literature}

This performance criterion determines the extent to which students are able to (i) identify the types of information needed for a complete understanding of all aspects of the project (based on tasks described in the project planning), (ii) gather information on relevant fundamentals, theory / concepts, similar existing systems (demonstrate technical competence) and relate them to the design, and (iii) provide the sources in a list of references properly cited in the literature review section and relevant sections of the report.

\section{Ability to generate ideas and apply creativity}

This is assessed by determining ability of students to (i) define functional requirements for design (specific required actions needed to be performed for the design to be achieved), (ii) transform functional requirements into candidate solution concepts / mathematical modeling, and (iii) evaluate candidate solutions to arrive at feasible designs.

\section{Ability to perform preliminary and detailed design}

Students are able to (i) perform relevant analysis (engineering, mathematical, economic), (ii) develop final design specifications, and identify applicable codes and standards for the design, apply and evaluate realistic constraints (which may include regulations, design, economic, environmental, health, manufacturability and safety constraints considered in design, professional, ethical, social \& political issues in design). (iii) select materials, components, software, and test equipment, (iv) fabricate a prototype or a model (physical, software, or hardware) of the design, test or simulate the design and make necessary changes to obtain optimum design.

\section{Performance Criteria for Outcome Group 4}

Outcome group 4 consists of (1) EAC Criterion 3, outcome d, "an Ability to function on multidisciplinary teams ", (2) TAC Criterion 3, outcome e, "an ability to function effectively on teams, and (3) CAC Criterion $3 \mathrm{~d}$, "an ability to function effectively on teams to accomplish a common goal. Five performance criteria were developed for this outcome. The performance criteria measure students ability to:

1. Plan group meetings and time management and assign team roles (leader, recorder, etc)

2. Distribute project tasks evenly to team members

3. Resolve conflicts professionally within the group (Example will be an assignment to identify potential problems and indicate how they will resolve them)

4. Track progress of team members to ensure project is on schedule (Through submission of progress reports)

5. Share ideas, complete assigned task on time, help others, and be professional to each other (through peer evaluation of team members on these characteristics)

Ohland et. $a l .{ }^{6}$ have developed a peer evaluation instrument that collected student ratings on five factors using a BARS scale for this outcome.

\section{Performance Criteria for Outcome Group 5}

Outcome group 5 consists of (1) EAC Criterion 3, outcome e, "an ability to identify, formulate, and solve engineering problems", (2) TAC Criterion 3, outcome f, "an ability to identify, analyze 
and solve technical problems, and (3) CAC Criterion 3, outcome d, "an ability to analyze a problem, and identify and define the computing requirements appropriate to its solution".

\section{Ability to identify engineering/technical/computing problems}

Given a problem, the student is able to (i) understand the given problem and identify the subject area and concept involved, (ii) convert the problem into a well labeled sketch (such as free body diagram, flow chart, functional block diagram, schematic diagram), and (iii) identify the system of units applicable to the problem

\section{Ability to formulate/analyze engineering/technical/computing problems}

Given a problem, the student is able to (i) define the known and the unknown variables in the problem, (ii) state relevant laws and equations needed for the problem, (iii) list and apply assumptions to the relevant laws and equations to obtain the specific equations appropriate to the problem.

\section{Ability to solve engineering/technical/computing problems}

Given a problem, the student is able to (i) implement strategy to solve the problem, (ii) solve the problem (showing consistent units throughout), and (iii) evaluate and interpret the results.

\section{Performance Criteria for Outcome Group 6}

Outcome group 6 consists of (1) EAC Criterion 3, outcome f, "an understanding of professional and ethical responsibility", (2) TAC Criterion 3, outcome i, "an ability to understand professional, ethical and social responsibilities, and (3) CAC Criterion 3, outcome e, "an understanding of professional, ethical, legal, security and social issues and responsibilities".

\section{Students understand and demonstrate ethical responsibilities}

This performance criterion is measured by ascertaining if (i) students are able to demonstrate the knowledge of professional code of ethics (Review code of ethics from one's specific professional society and from the State board of professional Engineers. Students may be tested on these), (ii) students are able to evaluate case studies and make ethical decisions ( Instructor may present a case study and request students to identify and provide professional and ethical considerations for addressing the problem posed in the case study), (iii) students acknowledge the work of others they use through proper permission and citation, and (iv) students apply ethics in the academic environment and desists from cheating, plagiarism, and reports such unethical practices to proper authorities.

\section{Students understand and demonstrate professional responsibilities}

This performance criterion is assessed by determining if students (i) apply professional standards (use of handbooks, codes, standards) in obtaining, reporting, analyzing data or in design, (ii) attend classes on regular basis and inform professor when excused absence situation occurs (one can use attendance policy and the professionalism of students in informing and getting excuse for being absent), and (iii) students demonstrate high academic standards, personal responsibilities (continually looks for own mistakes and opportunities/methods for improvement), and exercises good judgment and discretion (make decisions based upon a defined body of acquired knowledge) 


\section{Students understand and demonstrate social responsibilities}

This performance criterion is assessed by ascertaining the extent to which (i) students consider and evaluate short and long term impact of a solution on society and environment in arriving at a final solution ( Students may be required to evaluate the impact of their solutions on the local, national, or global society), and (ii) students are cognizant of the importance of proper engineering knowledge in ensuring the public safety in all engineering designs and decisions they make (the need to use standards, and to design and build as safe as possible).

\section{Performance Criteria for Outcome Group 7}

Outcome group 7 consists of (1) EAC Criterion 3, outcome g, "an ability to communicate effectively", (2) TAC Criterion 3, outcome g, "an ability to communicate effectively", and (3) CAC Criterion 3, outcome $\mathrm{f}$, "an ability to communicate effectively with a range of audiences". Two sets of performance criteria were developed for this outcome group, one set for oral communication and one group for written communication. The performance criteria for the written communication is based not only on formatting and English details of the report, but also on the structure, and technical details required in a senior design project technical report as required by the senior projects report manual ${ }^{7}$ for the College of Engineering at Prairie View A\&M University.

\section{Performance Criteria for Oral Communication}

The four performance criteria for oral communication are:

\section{Ability to organize and plan communication/presentation}

This performance criterion is assessed by determining the extent to which (i) students are able to organize presentation in well structured logical sequence making it easy for audience to follow the content with clear understanding, and (ii) students are able to stay within time limits.

2. Ability to demonstrate subject knowledge and provide sufficient technical content This performance criterion is assessed by determining the extent to which (i) students demonstrate knowledge and understanding of the subject, (This may be demonstrated by presenting literature review, originality, creativity, required standards, constraints, and other appropriate considerations such as economics, environmental, and societal impact), and (ii) students respond clearly to questions after restating questions to the audience

\section{Appearance and ability to provide good oral delivery}

This performance criterion is assessed by determining if students are able to: (i) use correct grammatical English and technical terms appropriate to technical area and audience, and speak with clarity and confidence, (ii) maintain good posture and eye contact with the audience ( should not read from prepared notes) and elicit the attention of the audience, and (iii) dress appropriately for the occasion. 


\section{Ability to design/prepare and use appropriate visual aids}

This performance criterion measures the extent to which students are able to (i) prepare effective slides (adequate and relevant technical content, and viewgraphs that are legible, completely labeled/annotated/dimensioned to illustrate important features of the work being presented), (ii) use modern presentation techniques (may include visually enhanced transitions, animations, video, and sound clips), and (iii) prepare and display prototypes or models when necessary.

Instructor may record the presentation for assessment display purpose, and must ensure to get consent for witness protection from the students.

\section{Written Communication (Through Senior Project Report Writing)}

Six performance criteria were developed for this outcome based on the requirements in the Senior Design Projects manual ${ }^{5}$. The four performance criteria and the components used to assess them are:

1. Students are able to prepare a well organized and well formatted technical report This performance criterion is assessed by determining how well the written report is formatted. The elements considered include ascertaining whether students (i) provide title page, abstract, table of contents, list of figures, and list of tables, (ii) provide figure numbers and titles, including discussing and referencing each figure in the text, (iii) provide table numbers and titles, including discussing and referencing each table in the text, (iii) properly cite references in the report and provide well formatted reference list at the end, (iv) provide appropriate and logical sub-headings under each section of the report, and (v) prepare the written report in accord with standard report formatting provided in the Senior Projects Report Manual ${ }^{5}$.

\section{Students are able to use correct English grammar, spelling, and punctuations.}

\section{Students are able describe in details, their understanding of the problem and provide} project plans.

This performance criterion is assessed by determining if important sections are included in the report and how well these sections are written. The major report sections used to evaluate this performance criterion include: (i) project scope where we look at how well students are able to define and describe the scope of the work being reported (may include having sections on Problem Statement, Client Identification \& Recognition of need, Recognition of \& Knowledge of Relevant Contemporary Issues, and clearly indicating Goals and Objectives of the work being reported), (ii) project plans and tasks, where we look at how well students are able to (a) plan and track project by providing task identification, specifying deliverables, timeline, and Gantt chart, and (b) use modern project planning tools (such as Microsoft Project Software) for planning, tracking, and execution of the project, (iii) the literature reviewed where we look at how well students are able to (a) describe relevant topics for literature review, (b) describe previous design or related materials, (c) describe the relevance of materials reviewed to project, and (d) properly cite the references used for literature review. 


\section{Students are able to present preliminary design}

The elements used to assess this performance criterion include (i) description of design concepts, their evaluation, and rational for selecting best alternative, (ii) description of engineering specifications and preliminary design analysis, and (iii) description of constraints (which may include sections describing Regulations \& Design Constraints considered in design, Economic, Environmental, Health, manufacturability \& Safety constraints considered in design, Professional and Ethical Issues considered in Design as well as Social \& Political Issues considered in design).

\section{Students are able to present detailed system design/fabrication and technical details in the report}

This performance criterion is assessed by ascertaining how well students are able to (i) present in-depth analyses that consider regulations, codes and standards, constraints, objectives, and goals, (ii) describe the use of modern tools in the analysis and design, drawings/schematics/ solid models, simulation and prototype or model development, (iii) clearly describe economic analysis that may include fixed, running cost, amortized cost, unit cost, and other economic considerations, (iv) describe the fabrication/Assembly/Simulation/Testing of the Model or Prototype, and (v) document the physical or computer model, test results, and design verifications.

\section{Ability to provide appropriate discussion, conclusions and recommendations}

This performance criterion is assessed by determining how well students are able to clearly (i) summarize the goals, Objectives, and indicate whether they were met, (ii) summarize constraints and codes and indicate whether they were met, and (iii) provide logical conclusions and recommendations (including strengths and weaknesses).

\section{Performance Criteria for Outcome Group 8}

Outcome group 8 consists of (1) EAC Criterion 3, outcome h, "the broad education necessary to understand the impact of engineering solutions in a global, economic, environmental, and societal context", (2) TAC Criterion 3, outcome j, "respect for diversity and a knowledge of contemporary professional, societal and global issues, and (3) CAC Criterion $3 \mathrm{~g}$, "an ability to analyze the local and global impact of computing on individuals, organizations, and society .The single performance criterion for this outcome group measures the extent to which

1. Students are able to investigate a given engineering problem and are able to analyze the short and long term impact (political, economic, environmental, health, safety, cultural) of proposed solutions on society (individual, local, regional or global context).

Some of the possible approaches for assessing this performance criterion are provided below

- Instructor poses a problem (case study), and asks students to propose solution and indicate how proposed solution will impact society

- Instructor poses a problem, provides solutions, and asks students to analyze solutions and determine their impact on society. 
- Students working on projects are required to analyze and determine the effects of their proposed solution on society

\section{Performance Criteria for Outcome Group 9}

Outcome group 9 consists of (1) EAC Criterion 3, outcome i, "recognition of the need for, and the ability to engage in life-long learning ", (2) TAC Criterion 3, outcome h, "recognition of the need for, and the ability to engage in life-long learning", and (3) CAC Criterion 3, outcome h, "Recognition of the need for, and an ability to engage in continuing professional development"

Four performance criteria were developed for this outcome group. The four criteria are:

1. Students are able to effectively use library and online resources for research and are abreast with current developments in their discipline. (Instructor can give an assignment requiring students to use other resources to study on their own and use the information studied to solve the problem, or give a library assignment)

2. Students join and participate in activities of local student chapters of professional or other organizations and be aware of or make use of programs provided by the professional organizations in the areas of training and continuing education.

3. Students are able to identify and take advantage of learning opportunities available on internet and elsewhere such as seminars, webinars, conferences, workshops and tutorials.. (The instructor should direct the students to identify some of these activities and require them to show documentation of their involvement).

4. Given an open ended problem, students are able to independently acquire additional knowledge and data needed for solving the problem. (Instructor may give an assignment that requires students to learn additional information not covered in class for successful completion of the assignment)

\section{Performance Criteria for Outcome Group 10}

Outcome group 10 consists of (1) EAC Criterion 3, outcome j, "Knowledge of Contemporary Issues", and (2) TAC Criterion 3, outcome j, "a respect for diversity and a knowledge of contemporary professional, societal and global issues,

The two performance criteria developed for this outcome group are:

1. Student are able to identify current issues (socio-economic, political, environmental, cultural, health and safety) in engineering and technology. Some examples are global warming, population, depletion of natural resources, alternative energy; outsourcing, security, ecology, engineering/technology workforce development, human rights and environmental pollution.

2. Students are aware of contemporary issues in industry such as corporate culture, industry-academia-government collaboration, industrial competition, etc. 
(Instructor may require the student to identify and discuss several of the contemporary issues; recognize consequences; take and defend a position and/or write a report. Instructor may assign topics or issues and require the students to discuss these issues; recognize consequences; take and defend a position and/or write a report).

\section{Performance Criteria for Outcome Group 11}

Outcome group 11 consists of (1) EAC Criterion 3, outcome k, "An ability to use the techniques, skills, and modern engineering tools necessary for engineering practice", (2) TAC Criterion 3, outcome a, "an appropriate mastery of the knowledge, techniques, skills and modern tools of their disciplines, and (3) CAC Criterion 3, outcome i, "An ability to use current techniques, skills, and tools necessary for computing practice".

Three performance criteria listed below were developed for this outcome group.

1. Students are able to solve problems using current software used in the discipline (such as Matlab, autocad, EES, Ansys, Multisim, Pspice, .NET, C++ compiler, etc)

2. Students are able to utilize the latest available hardware/equipment used in the discipline (such as NC machine, signal generators, oscilloscope, strength testing machine, computer hardware)

3. Students are able to utilize latest problem solving and design techniques/methods in their discipline (such as unified modeling language (UML), numerical techniques, process simulators, and the design process)

\section{Performance Criteria for Outcome Group 12}

Outcome group 12 consists of TAC Criterion 3, outcome k, "a commitment to quality, timeliness, and continuous improvement".

The three performance criteria used to assess this outcome are listed below:

1. Students prepare and submit assignments of professional quality (uses appropriate media)

2. Students keep and follow time schedules for their studies and other activities, are punctual, and complete homework and other assignments on time.

3. Students strive to and are able to demonstrate academic progress.

\section{Guidelines for using the performance criteria}

The performance criteria described and numbered with Arabic numbers (such as 1, 2, 2.1, etc.) are assessed individually. Statistical class averages, and percent of students with averages at or above the departmental expected average are reported for each of these performance criteria.

The class average for all performance criteria listed under an outcome are computed and used as the measure for the outcome. The percentage of students with average at or above the departmental expected average are also reported for each outcome and used to ascertain the extent to which the outcome is met by the department or program. 
All items with Roman numbers (such as i, ii, iii, etc.) are considered as guides or basis for assessing the performance criteria. Statistical class averages are not reported for these.

Each outcome has anywhere from one to eleven performance criteria that may have to be assessed. Working on the premise that a program does not have to assess every course every semester, or every outcome in a course in a given semester, an opportunity to reduce the amount of work needed for assessing the outcomes exists. However, to ensure that adequate statistical records are maintained for the outcomes and their representative performance criteria, detailed advanced planning by programs are required.

The conditions under which an outcome and its performance criteria are assumed to have been met have to be clearly defined by a program. Such conditions can be expressed by statement such as "The acceptable class average for an outcome and its performance criteria for the program is $75 \%$, and an outcome or a performance criteria would be met if at least $70 \%$ of the students meet or exceed this average".

\section{Conclusions}

The assessment committee in the College of Engineering at Prairie View A\&M University has presented detailed performance criteria that can be used to assess EAC, TAC and CAC recommended program outcomes and in accord with the assessment process ${ }^{8}$ developed in the College of Engineering. Prior to the definition of these performance criteria, different faculty members were assessing the outcomes using their own interpretation of the outcomes, and consequently, it was not exactly clear what those numbers really meant, or what specific areas the students were weak in. This made it difficult to identify true program weaknesses, and appropriate changes to improve the program.

With the definition of the performance criteria for each outcome, there is now a common understanding of what specifically goes to measure an outcome, and all faculty use the same measures. Thus the assessment numbers are now meaningful. For each outcome, we can now look at the students' progress in each performance criteria area, and consequently, can identify the performance area needing improvement in the program.

In conclusion, the methodology for defining and using the performance criteria enables faculty to (1) fully understand the outcomes, (2) understand a range of performance criteria that need to be measured for each outcome. It also removes any ambiguity in the interpretation of the outcomes. In addition, it makes it possible to identify the critical skill-sets to measure for each outcome and makes assessment meaningful to the various programs because it is possible to identify the performance area needing improvement. 


\section{References}

1. Koehn, Enno, “ABET Program Criteria: Review and Assessment for a Civil Engineering Program”, Journal of Engineering Education, July 2001, pp 445-455.

2. Rennels, K., "Outcomes Assessment in an MET Program", Proceedings of the 2002 American Society for Engineering Education Annual Conference \& Exposition, American Society for Engineering education.

3. Deng, Z.T., Ruben, R, Qian, X., "Developing Assessment Tools for Outcome Based Engineering Courses", Proceedings of the 2002 American Society for Engineering Education Annual Conference \& Exposition, American Society for Engineering Education

4. Erdogan, M.S., "Assessment: How Much is Too Much or How Much is Not Enough?" Proceedings of the 2002 American Society for Engineering Education Annual Conference \& Exposition, American Society for Engineering education.

5. Fielder, Richard M., Brent, Rebecca; "Designing and Teaching Courses to Satisfy the ABET Engineering Criteria", Journal of Engineering Education, January 2003. Also available at online at <http://www4.ncsu.edu/unity/lockers/users/f/felder/public/Papers/ABET_Paper_(JEE).pdf >, accessed on $02 / 25 / 08$

6. Ohland, Matthew W., Loughry, Misty L., Carter, Rufus L., Bullard, Lisa G., Felder, Richard M., Finelli, Cynthia J., Layton, Richard A., and Schmucker, Douglas G. Schmucker, "Developing a Peer Evaluation Instrument that is Simple, Reliable, and Valid", Proceedings of the 2005 American Society for Engineering Education Annual Conference \& Exposition Copyright (C) 2005, American Society for Engineering Education. Also available at online at $<$

http://www.foundationcoalition.org/home/keycomponents/assessment_eval/Developing_a_P eer_Evaluation_Instrument_that_is_Simple_Reliable_and_Valid.pdf $>$, accessed on 02/25/08.

7. Biney, P.O., Lin, S.B; Attia, J.O., Osborne-Lee, Perkins, J., Gyamerah M., and Lodgher A., "Senior Design Projects Manual", College of Engineering, Prairie View A\&M University, 2004.

8. Biney, Paul, and Bryant, Milton., "A Novel Strategy for the Direct Assessment and Improvement of Engineering Programs Developed and Implemented by the College of Engineering, Prairie View A\&M University". 